\title{
Prioritizing the patient: optimizing therapy in rheumatoid arthritis. Results of a patient questionnaire in northern Germany
}

This article was published in the following Dove Press journal:

Open Access Rheumatology: Research and Reviews

15 May 2013

Number of times this article has been viewed

\section{Jürgen Wollenhaupt' Inge Ehlebracht-Koenig ${ }^{2}$ André Groenewegen ${ }^{3}$ Dieter Fricke ${ }^{4}$}

'Rheumatologikum Hamburg, Schön Klinik Hamburg Eilbek, Hamburg, Germany; ${ }^{2}$ Center of Rehabilitation, Bad Eilsen, Germany; ${ }^{3} U C B$ Pharma SA, Brussels, Belgium; ${ }^{4} U C B$ Pharma $\mathrm{GmbH}$, Monheim, Germany
Correspondence: Jürgen Wollenhaupt Rheumatologikum Hamburg, Dehnhaide I20, 2208I Hamburg, Germany

Tel +49402092 | 35 |

Fax $+49402092 \quad$ I350

Emailwollenhaupt@rheumatologikum.de
Purpose: A 40-question postal survey was developed to gain insight into the nature of difficulties experienced by patients due to rheumatoid arthritis (RA), as well as patient perceptions and priorities regarding their RA treatment

Patients and methods: A total of 3000 Lower Saxony, Germany members of Rheuma-Liga $(\mathrm{RL})$, a patient support group for people with RA, were invited to participate between July 1, and August 20, 2009. The questionnaire was divided into four sections: (1) patient demographics, (2) quality of life (QOL), (3) treatment expectations and, (4) patient perceptions of RL. The questionnaire could be completed in writing or via the internet.

Results: Of 959 respondents (response rate $=32.0 \%$ ), 318 had diagnosed RA and were included in the analysis. The respondents were mostly retired $(71.2 \%)$, female $(83.3 \%)$, and $>60$ years of age (63.5\%). Members' responses indicated that most were generally satisfied with their current treatment $(67.3 \%)$, considered it efficacious $(84.0 \%)$, and reported minimal (none or little) side-effects $(61.2 \%)$. Patient involvement in treatment decisions, however, was reportedly low (49.6\% felt insufficiently involved). Patients' primary impairments were reflected in their treatment priorities: mobility (97.0\%), ability to run errands/do shopping $(97.1 \%)$, do the housework (95.6\%), and be independent of others $(94.2 \%)$. The primary service provided by RL and used by respondents was physiotherapy (70.6\%), which was reported to benefit physical function and mood by over $90.0 \%$ of respondents.

Conclusion: RA had a detrimental effect upon respondents' quality of life, specifically impairing their ability to perform daily tasks and causing pain/emotional distress. Independence and mobility were strong priorities for respondents. Physical therapy, provided by RL, was felt to help both physical and mental/emotional health.

Keywords: rheumatoid arthritis, patient survey, quality of life, patient satisfaction

\section{Introduction}

Rheumatoid arthritis (RA) is a progressive, inflammatory disorder, leading to joint degradation and functional impairment. ${ }^{1}$ The condition is associated with increased mortality through development of cardiovascular disease (CVD) with accelerated atherosclerosis. ${ }^{2,3}$ Consensus from numerous studies in developed-world populations suggests that the current prevalence of RA is between $0.5 \%$ and $2.0 \%$ of the adult population, and that this figure has begun to increase in recent years. ${ }^{2,4,5}$ Risk factors for RA include gender (prevalence of RA female:male, $3: 1$ ), age (peak incidence at 55-64 years of age for women, 65-74 years of age for men), and smoking. ${ }^{6}$

RA has a substantial impact upon patients' quality of life (QOL) as a result of continuous pain, functional disability, reduced mobility and loss of independence in daily 
life. ${ }^{7,8}$ Increasing pain is associated with a higher degree of depression, even amongst patients who feel their condition to be well controlled. ${ }^{9}$ Indeed, much of the patient's burden from RA results from its impact upon the patients' overall sense of well-being; consequently, the use and acceptance of QOL measures in assessing treatment efficacy in RA has become an increasingly important measure of patient health. ${ }^{10-13}$ The five most important outcomes for RA patients are: pain, joint damage, fatigue, activities of daily living and mobility. ${ }^{14,15}$ In addition, patient reported outcomes (PROs) have been shown to be an important indicator for long-term disease progression. ${ }^{16}$ The importance of these aspects has recently been emphasized by EULAR (the European League Against Rheumatism) when consideration of patients' perspectives and priorities in treatment decisions was defined as one overarching principle of care for RA patients. ${ }^{17}$

While changes in the QOL of RA patients have been studied extensively in clinical trials, relatively little information is available for real-life RA patient populations. Indeed, publications on RA patients have noted that randomized controlled clinical trials do not truly reflect the spectrum of real-life patients encountered in the clinic, for example because their disease activity is lower or higher, they have more/other comorbidities and use more/other concomitant medications. ${ }^{18-21}$ Therefore, analysis of real-life data is of use for comparison with that reported from clinical results and may more accurately reflect the broader patient population, regardless of potentially confounding factors that are typically and necessarily avoided when defining clinical study populations. Here we report the results of a patient questionnaire obtained from members in Lower Saxony, Germany of a patient organization for rheumatic diseases (Rheuma-Liga, RL). As optimal treatment requires a clear understanding of the patients' needs, the aim of this study was to assess patients' QOL as well as their perceived needs and expectations for treatment and support.

\section{Materials and methods}

\section{Rheuma-Liga and patient selection}

The survey was developed to obtain feedback from the RL members with regard to the extent and nature of their functional impairment and disabilities due to RA, as well as their perception and priorities in terms of their overall RA treatment, and support services provided by RL. The aims of the RL organization are to raise awareness about rheumatic and musculoskeletal diseases (RMDs), improve the QOL for people with RMDs and campaign for the improvement of medical treatment, psychological, and social support.
The RL is an independent organization and has 16 regional sections which comprehensively cover Germany. In total, RL has about 260,000 members and is the largest patient organization in Germany. Between July 1 and August 20, 2009, 3000 of the 55,000 members of RL in Lower Saxony were randomly selected from the member list. A written questionnaire in German language was sent by mail. Patients had the option of returning the completed questionnaire by post or completing the questionnaire online.

\section{Questionnaire structure}

The RL questionnaire comprised 40 questions divided into four sections relating to: (1) patient demographics, (2) QOL in RA, (3) treatment expectations, and (4) patient perceptions of RL. The questionnaire, translated into English from the original German, is provided in full in Appendix 1. All responses, including medical histories, and diagnostic and therapeutic information, were provided directly by the respondents without guidance of medical personnel.

\section{Section I: patient demographics}

Questions 1 to 8 recorded patients demographics and medical history including gender, age group, employment status, type of rheumatic condition, severity of rheumatic disease, time since diagnosis and age at time of RA diagnosis.

\section{Section 2: quality of life in RA}

Questions 9 to 19 related to QOL and were derived from the validated measures Nottingham Health Profile (NHP) ${ }^{22}$ and SF-36 Health Survey, ${ }^{23}$ although were not validated in the adapted format used; license agreement for use of sections from the SF-36 was obtained from Quality-Metric Inc, (Lincoln, RI, USA). Patients were asked to use subjective scales to assess their impairment.

Briefly, questions 9 to 15 assessed general health, impact of RA on the patients' life and mental health, current QOL, perception of pain, work-related productivity, and social participation. Questions 16 to 18 assessed the patient's ability to perform everyday tasks/activities and the degree of their dependence upon others in their daily lives. Finally, question 19 asked patients to personally rate the importance of specific aspects of daily living.

\section{Section 3: treatment expectations}

Questions 20 to 27 related to patients' current treatment and treatment perceptions (assessed using subjective scales).

Questions 20 to 24 recorded what type of medication patients' were currently using, how satisfied they were with 
their current therapy, their degree of involvement in therapy decision making, the efficacy of their current therapy (in terms of maintaining their lifestyle, reducing pain, slowing joint damage, and avoiding disability) and the impact of treatment side-effects on their health/activity.

Question 25 investigated what facets of an "ideal" treatment were rated as most important by patients. These included rapid symptom relief/rapid signs of improvement, persistence of positive results/no loss of efficacy, simplicity of use, absence of side-effects/no injection site skin reaction, low dose/no need for future increase in dose, administration route/ simple to self-administer/no requirement for hospitalization/ can be self-administered without assistance, treatment costs and need only take/administer infrequently.

Questions 26 and 27 asked patients what type of treatment they preferred (ie, daily tablets, subcutaneous injection [home or in hospital], intravenous injection [hospital]) and how important self-administration was regarded.

\section{Section 4: patients' perception of RL}

Questions 28 to 40 related to patients' perceptions of RL and the services it offered to members. These questions asked what reasons patients might have to recommend RL to others, which RL services were of highest importance, how aware patients were of the services offered by RL, how they found out about RL, what services were offered and/ or used by the members, and what future activities were of interest to the members.

Full details of all questions and subjective response scales can be found in Appendix 1.

\section{Statistics}

Descriptive comparisons were used for all individual questionnaire items.

\section{Results}

\section{Demographics}

In total, 959 of 3000 patients responded to the questionnaire (response rate $=32.0 \%$ ); of these, $318(34.3 \%)$ had diagnosed RA and were included in this analysis. A detailed summary of patient demographics is presented in Table 1. The majority of RA patients were female ( $83.3 \%$ vs $16.7 \%$ males) and nearly two-thirds $(63.5 \%)$ of respondents were $\geq 60$ years old. Most respondents were retired (71.2\%). The majority of respondents reported severity of rheumatic disease of either moderate $(58.5 \%)$ or severe $(27.5 \%)$, with age at onset most commonly reported as between $40-49$ years $(29.7 \%)$ or $50-59$ years $(30.1 \%)$.
Table I Questions 2-8: demographic characteristics of respondents with rheumatoid arthritis (RA)

\begin{tabular}{|c|c|c|}
\hline Parameter & $\mathbf{n}$ & $\%$ \\
\hline \multicolumn{3}{|l|}{$\operatorname{Sex}(N=318)$} \\
\hline Male & 53 & 16.7 \\
\hline Female & 265 & 83.3 \\
\hline \multicolumn{3}{|l|}{ Age (years) $(\mathrm{N}=3 \mid 8)$} \\
\hline$<20$ & 0 & 0 \\
\hline $20-29$ & 3 & 0.9 \\
\hline $30-39$ & 6 & 1.9 \\
\hline $40-49$ & 32 & 10.1 \\
\hline $50-59$ & 75 & 23.6 \\
\hline$\geq 60$ & 202 & 63.5 \\
\hline \multicolumn{3}{|l|}{ Occupation ( $N=3 \mid 3)$} \\
\hline Employee & 52 & 16.6 \\
\hline Self-employed & 7 & 2.2 \\
\hline Retired & 223 & 71.2 \\
\hline Student & I & 0.3 \\
\hline Unemployed & 6 & 1.9 \\
\hline Unfit for work & 5 & 1.6 \\
\hline Other & 19 & 6.1 \\
\hline \multicolumn{3}{|l|}{ Type of rheumatic disease $(\mathrm{N}=3 \mid 8)$} \\
\hline Rheumatoid arthritis & 318 & 100.0 \\
\hline Osteoarthritis/degenerative joint diseases & 113 & 35.5 \\
\hline Ankylosing spondylitis & 15 & 4.7 \\
\hline Juvenile arthritis & 1 & 0.3 \\
\hline Fibromyalgia & 51 & 16.0 \\
\hline Psoriatic arthritis & 17 & 5.3 \\
\hline Other & 3 & 0.9 \\
\hline \multicolumn{3}{|l|}{ Severity of RA disease $(N=3 \mid 3)$} \\
\hline Very mild & 0 & 0 \\
\hline Mild & 30 & 9.6 \\
\hline Moderate & 183 & 58.5 \\
\hline Severe & 86 & 27.5 \\
\hline Very severe & 14 & 4.5 \\
\hline \multicolumn{3}{|l|}{ Time since RA diagnosis $(N=316)$} \\
\hline$<$ I years & 6 & 1.9 \\
\hline $\mathrm{I}-3$ years & 24 & 7.6 \\
\hline $3-5$ years & 39 & 12.3 \\
\hline $5-10$ years & 79 & 25.0 \\
\hline$>10$ years & 168 & 53.2 \\
\hline \multicolumn{3}{|l|}{ Age at time of RA diagnosis $(\mathrm{N}=3 \mid 6)$} \\
\hline$<20$ years & 18 & 5.7 \\
\hline 20-29 years & 22 & 7.0 \\
\hline $30-39$ years & 46 & 14.6 \\
\hline $40-49$ years & 94 & 29.7 \\
\hline $50-59$ years & 95 & 30.1 \\
\hline$\geq 60$ years & $4 I$ & 13.0 \\
\hline
\end{tabular}

\section{Details of current therapy}

Overall $69.4 \%$ of respondents used analgesics for treatment of their RA, $47.4 \%$ used disease-modifying antirheumatic drugs (DMARDs), 39.8\% used corticosteroids, $16.1 \%$ used non-steroidal anti-rheumatics, and $7.9 \%$ used biological therapies such as tumor necrosis factor (TNF) inhibitors. 


\section{Efficacy and tolerability of current treatment}

Most respondents (84.0\%) rated treatment efficacy as sufficiently effective (ie, improvement) and only $6.8 \%$ reported a worsening of their RA under treatment (Table 2). Consistent with this, $67.3 \%$ of respondents were "satisfied" with their current therapy, $22.3 \%$ were indifferent ("neither satisfied nor dissatisfied"), and $10.4 \%$ were "dissatisfied".

In addition, the majority of respondents (61.2\%) reported either "none" $(17.8 \%)$ or "barely noticeable/does not really bother me" (43.4\%) side-effects of their current treatment. However, 9.2\% of respondents rated side-effects as "occasionally interfering with their daily activities," $3.0 \%$ reported side-effects as "frequently interfering with daily activities," and $0.3 \%$ recorded that their side-effects were "intolerable".

\section{Involvement of patients in treatment decisions}

The overall involvement of respondents in their treatment decisions was unexpectedly low, and $49.6 \%$ of respondents felt they were insufficiently involved in decision making by their rheumatologists ("no or little involvement"). In contrast $19.7 \%$ reported that they felt "very much" involved.

\section{Patients' priorities for future treatments}

More than $80 \%$ of respondents considered the following aspects of treatment to be very important for any potential treatment of RA: persistence of positive clinical response for more than one year (92.0\%), absence of side-effects $(89.2 \%)$, no loss of response over time ( $82.9 \%)$, simple to self-administer $(82.3 \%)$, and no need for hospitalization (80.4\%). In addition, the preferred form of treatment administration was a single tablet daily (81.0\%), and $85.3 \%$ of respondents considered self-administration, without assistance, to be very important.

\section{Patient priorities for QOL}

Almost all respondents (97.7\%) reported that mobility inside and outside the home was of particular importance to

Table 2 Question 23: effect of current treatment $(\mathrm{N}=308)$

\begin{tabular}{ll}
\hline Treatment efficacy & $\%$ \\
\hline Dramatic improvement & 12.4 \\
Marked improvement & 26.9 \\
Somewhat improved & 44.8 \\
Somewhat worsened & 4.2 \\
Marked worsening & 2.3 \\
Dramatic worsening & 0.3 \\
\hline
\end{tabular}

them (Figure 1). Other activities rated to be at least "more or less important" by $\geq 90 \%$ of respondents included: the ability to run errands/do shopping (97.1\%), the ability to undertake housework (95.6\%), independence from others (94.2\%), and participation in normal social activities with family/friends (93.1\%).

\section{Patients' general QOL assessment}

For all QOL questions, overall responses from RA patients who reported an additional concomitant rheumatic disease were more negative (worse QOL) than from respondents with RA alone. Overall, $86.9 \%$ of respondents rated their general health as either "reasonable" or "good", and $87.6 \%$ rated their overall QOL as "reasonable" or "good" (Table 3). In contrast, $60.5 \%$ of respondents rated the impact of RA upon their lives as "rather bad" or "very bad" (Table 3).

\section{Pain and physical, or emotional, problems due to RA}

For $27.6 \%$ of respondents, the impact of RA on social activities during the previous month was "strong" to "very strong" (Table 4). In addition $49.6 \%$ reported their physical impairment in daily work (inside and outside the home) as "rather strongly" to "very strongly" impacted by RA (Table 4).

Overall, 25.9\% of respondents rated their pain over the previous month as "severe" to "very severe" (Table 4). Emotional problems due to RA (eg, depression or fear) were experienced regularly (ie, "all the time," "most of the time," or "sometimes") by $59.2 \%$ of respondents, "seldom" by $25.5 \%$, and "never/not at all" by $15.3 \%$.

\section{Impact of RA upon daily activities and independence}

Most activities of daily living could be performed "without any effort" or "with some effort" by $\geq 80 \%$ of respondents (Figure 2). Housework was possible "with a lot of effort" for $23.6 \%$ of respondents, while $5.2 \%$ of respondents reported being "unable" to do housework activities. Driving a car was reportedly not possible for $6.9 \%$ of respondents (ie, "unable"). Running errands and shopping was possible only "with a lot of effort" for $17.3 \%$ and impossible for $3.3 \%$ (ie, "unable").

Restriction in daily activities due to RA was frequently reported (Figure 3). For example: $95.8 \%$ of respondents reported restriction in strenuous/exhausting activities $(53.7 \%$ "very restricted" and 42.1\% "somewhat restricted"); $87.9 \%$ of respondents reported restriction in lifting/carrying shopping bags (30.2\% "very restricted" and 57.7\% "somewhat 


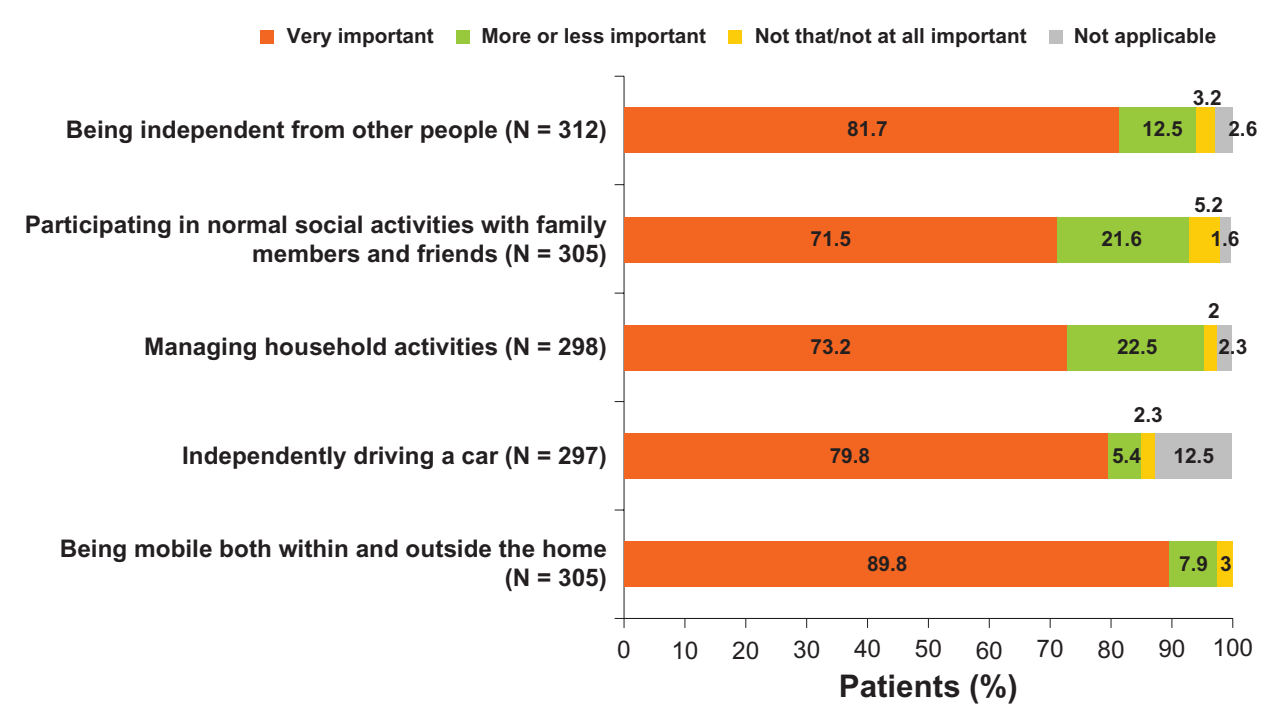

Figure I How important is independence to you?

restricted") and $81.1 \%$ of respondents reported restriction for moderately strenuous activities such as vacuum cleaning (16.3\% "very restricted" and 64.7\% "somewhat restricted").

Over $60 \%$ of respondents were at least "more or less" dependent upon a third-party in their day-to-day activities, generally upon their partner or family/friends (Table 5). In contrast, dependence upon medical personnel was markedly lower, with dependence highest upon "other medical specialist" (excludes "nurse/caregiver") (Table 5).

\section{Assessment of RL}

Respondents most commonly learned of RL from other members $(39.8 \%)$, their rheumatologist $(35.6 \%)$, or their general practitioner $(29.4 \%)$. In all $70.6 \%$ of respondents took advantage of RL's group physiotherapy program, and in most cases no further individual (ie, one-to-one) physiotherapy was offered by the treating physician. The group physiotherapy program was the most commonly stated (and generally the most important) reason for recommending RL

Table 3 Questions 9-II: general QOL assessment

\begin{tabular}{ll}
\hline General QOL assessment & $\%$ \\
\hline General health $(\mathrm{N}=3 \mid 4)$ & \\
$\quad$ Reasonable & 63.7 \\
Good & 23.2 \\
Impact of RA on life $(\mathrm{N}=3 \mid 4)$ & \\
$\quad$ Rather bad & 55.1 \\
$\quad$ Very bad & 5.4 \\
Overall QOL $(\mathrm{N}=3 \mid 6)$ & \\
$\quad$ Reasonable & 60.4 \\
Good & 27.2 \\
\hline
\end{tabular}

Abbreviations: RA, rheumatoid arthritis; QOL, quality of life. to other respondents (indicated by $86.5 \%$ of respondents). Furthermore, over $90 \%$ of respondents reported the physiotherapy program improved physical performance and mood, and reduced physical complaints.

Most respondents were aware of RL's different information services, and these were also a common reason for recommending RL to other respondents (68.8\%). Overall, $>80 \%$ of respondents were satisfied with the RL services. The interest in proposed new services was highest for medical support (physiotherapy 92.3\%), rehabilitation services (86.3\%), help obtaining second medical opinions (87.0\%), help communicating with the health insurance $(82.7 \%)$, and

Table 4 Impact of pain and physical/emotional problems

\begin{tabular}{ll}
\hline Pain and physical/emotional problems & $\%$ \\
\hline Impact of RA on social activities $(\mathrm{N}=3 \mid 2)$ & $3 \mid . I$ \\
Moderate & 23.1 \\
Strong & 4.5 \\
Very strong & \\
Impairment in daily work $(\mathrm{N}=3 \mid 2)$ & 34.6 \\
Moderate & 39.7 \\
Rather strong & 9.9 \\
Very strong & \\
Pain felt over previous month $(\mathrm{N}=3 \mid 2)$ & 50.6 \\
Moderate & 22.4 \\
Severe & 3.5 \\
Very severe & \\
Emotional problems due to RA $(\mathrm{N}=3 \mid 4)$ & 0.3 \\
All the time & 12.4 \\
Most of the time & 46.5 \\
Sometimes & 25.5 \\
Seldom & 15.3 \\
Not at all &
\end{tabular}

Abbreviation: RA, rheumatoid arthritis. 


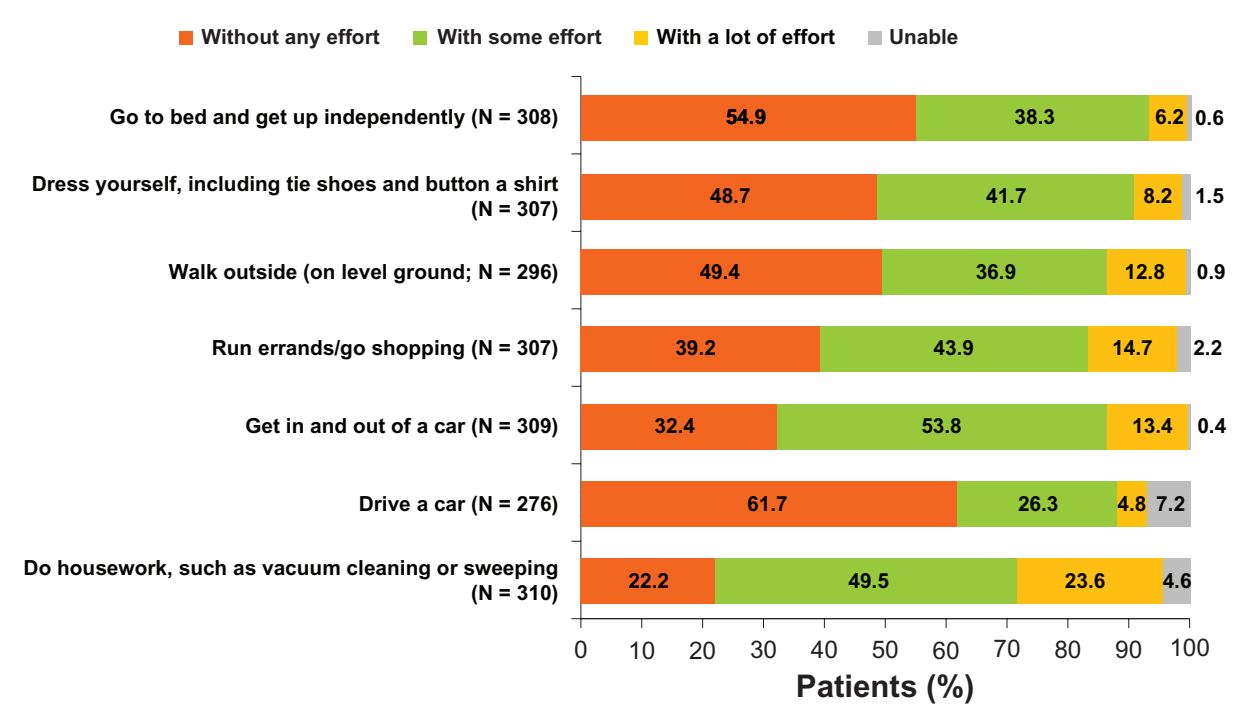

Figure $\mathbf{2}$ How much effort is required for you to undertake the following normal daily activities?

for courses about diet and rheumatism (88.6\%), and back training $(84.0 \%)$.

\section{Discussion}

This study was designed to provide a clearer understanding of patient priorities and needs amongst the members of an arthritis patient organization. For this purpose, a questionnaire was developed to obtain insight into patients' needs, their functional limitations and other disease associated aspects. It was not the intention to develop a new QOL assessment for RA respondents.

The resulting survey was relatively long (40 questions) and was sent to a randomly selected group of RL members who were asked to complete and return the questionnaire. Even though nearly one third of those invited did participate

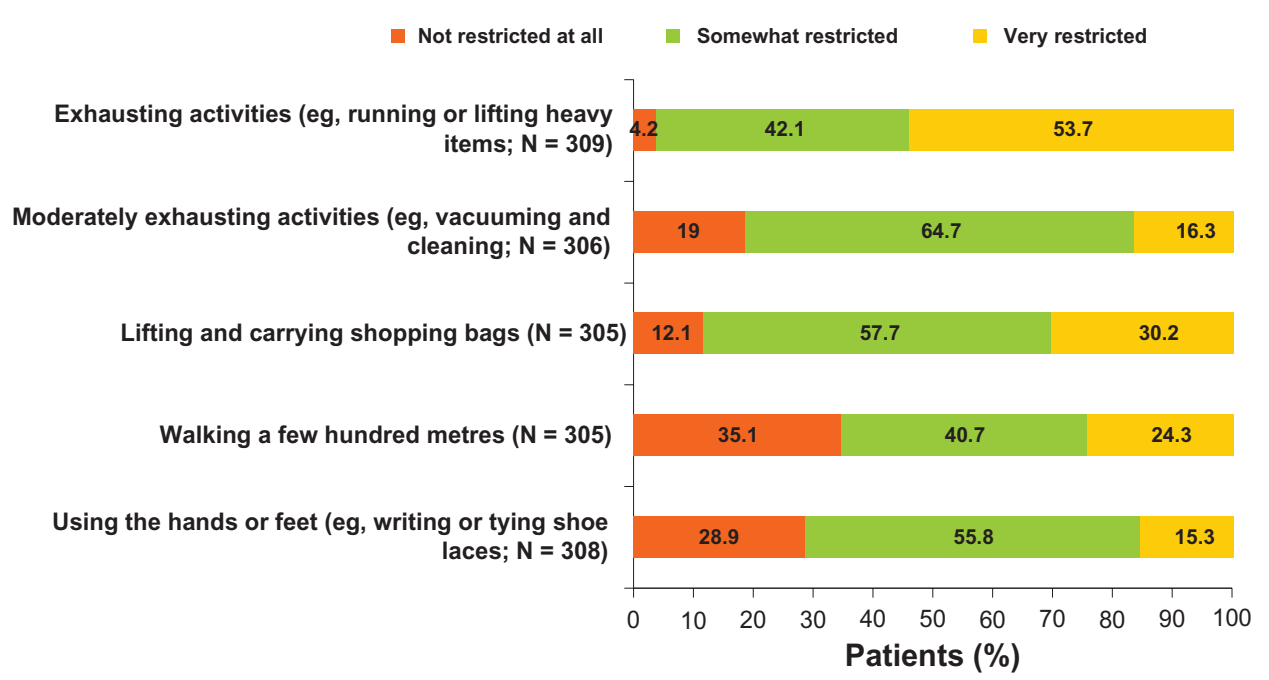

Figure 3 Is your health status restricting you in any way, and to what extent?

in the survey, the opinions obtained may reflect a selection of the most active or motivated members. This paper addresses only the results from those $34 \%$ of respondents who reported a diagnosis of RA, which may also limit conclusions.

As the survey used a non-validated questionnaire the responses were not calibrated to any clinical metric, therefore data could not be normalized against any other patient or healthy population responses and no domain-style summary analyses were possible. Data summaries and comparison were further limited by the lack of common scales between questions/sections. The results must therefore be considered on a subjective, question-by-question basis, and cannot be realistically assessed in a broader context. In addition, the participating population reflected the local RL membership and differed from observed broader RA populations; 
Table 5 Third-party dependence (\% respondents; $\mathrm{N}=262$ )

\begin{tabular}{llll}
\hline Dependence & Partner & $\begin{array}{l}\text { Familyl } \\
\text { friends }\end{array}$ & $\begin{array}{l}\text { Other medical specialist } \\
\text { (excludes “nurse/caregiver”) }\end{array}$ \\
\hline More or less & 53.7 & 42.5 & 8.4 \\
Heavily & 8.0 & 3.3 & 1.5 \\
\hline
\end{tabular}

for example, in gender ratio female:male (5:1 vs $2-3: 1$ expected), a median age $>60$ years, and a median time since diagnosis $>10$ years. ${ }^{6}$ As such, males, as well as younger patients and those patients with shorter disease durations, were under-represented. ${ }^{24,25}$ While this survey has provided important insight into specific RA patient issues, use of a validated assessment would have resulted in more representative data. For example, use of Short Form-36 (SF-36), ${ }^{23}$ which is known to be sensitive to clinically relevant signals in RA populations, ${ }^{13}$ or the SF-12 (a subset of the SF-36 questions), would improve the clinical relevance of the results of this survey. However, the questionnaire was designed to capture different aspects of the disease, including its burden and treatment aspects, as well as information about the performance of RL services. To include these domains, the questionnaire developed was felt to be the most practical way, even though this resulted in some limitations.

Despite these limitations, certain patterns were clear in the responses. In common with many QOL surveys of $\mathrm{RA},{ }^{7,26}$ participants stated that RA reduced their QOL and caused impairment in daily activities, including restricting their independence and mobility. Indeed, well over half the respondents were dependent upon a third party. Almost unanimously, respondents stated mobility and independence from other people were important to them. The burden of care fell largely upon family and friends rather than medical personnel, likely concealing much of the resulting cost burden.

Current guidelines from EULAR state that "best care" includes explicit patient involvement in treatment decisions. ${ }^{17}$ It was surprising then, that despite being satisfied with the clinical efficacy of their treatment approximately half of all respondents felt they were insufficiently involved in the clinical decision making process - which directly contradicts current best care guidelines. Increased patient involvement in decision making processes is important in improving patient's empowerment and may enhance treatment outcomes. ${ }^{27,28}$ While on the other hand, a lack of patient-doctor communication regarding RA treatment decisions is associated with increased incidence of moderate to severe depression. ${ }^{29}$ One possible limiting factor to full application of the concept of shared decision in the German clinic is the tight schedule for individual patient visits. This could be improved by increasing the number of physicians, introducing structured patient information and increasing involvement of assistants and nurses. ${ }^{30}$ With the development of therapeutic options like biologic agents rheumatologists acknowledge the need to involve the patients in the treatment decisions, as this has been shown to improve their adherence to therapy. ${ }^{31}$ Another driver to implement the concept of shared decision making could be the fact that patient participation is increasingly seen as a quality indicator for medical care within the German health care system. ${ }^{32}$

The survey results presented here also served to underline the importance of patient support groups, such as RL, as providers of services beneficial for patient health and QOL, such as physiotherapy (not otherwise provided through their physician) and of information on coping with their disease. These services empower patients and help them maximize their independence. In this survey, group physiotherapy was considered important to many respondents and was felt to improve their physical and mental health. It was also of note that assistance in communicating with medical staff (seeking second opinions) and dealing with health insurance companies were amongst the most strongly requested new services from RL. Taken together with the low patient involvement in clinical decisions, this suggests professional support services are still failing to fully engage this patient population, indicating a clear need for greater dialogue between patients (or patient organizations), physicians, and cost carriers/health care services.

Patient priorities of the assessed population were clearly focused on independence, but it remains to be investigated if a younger population would give a substantially different response in this regard. In addition, it may be that those who responded were different in important respects from non-responders, thus limiting the general applicability of the findings. Feedback from patients using the online version of the questionnaire was very poor, which may also suggest response was obtained from a subset population.

In summary, RA imposes a substantial physical and emotional burden upon patients. The highest priorities for patients, however, are mobility, independence, and coping with everyday activities. Physiotherapy and information services help patients cope with their condition day-to-day, and are primarily provided by patient support organizations such as RL. While generally satisfied with their treatment efficacy, patients may benefit from greater involvement in treatment decisions. 


\section{Acknowledgments}

This study was funded with an unrestricted educational grant by UCB Pharma GmbH to Rheuma-Liga. The authors acknowledge Costello Medical Consulting for editorial and administrative support.

\section{Disclosure}

J Wollenhaupt has served as an advisory board member and received honoraria as a speaker from UCB Pharma GmbH. D Fricke and A Groenewegen are employees of UCB Pharma. The authors report no other conflicts of interest in this work.

\section{References}

1. Klareskog L, Catrina AI, Paget S. Rheumatoid arthritis. Lancet. February 21, 2009;373(9664):659-672.

2. Ku IA, Imboden JB, Hsue PY, Ganz P. Rheumatoid arthritis: model of systemic inflammation driving atherosclerosis. Circ J. Jun 2009; 73(6):977-985.

3. Szekanecz Z, Koch AE. Vascular involvement in rheumatic diseases: 'vascular rheumatology'. Arthritis Res Ther. 2008;10(5):224.

4. Doran MF, Pond GR, Crowson CS, O'Fallon WM, Gabriel SE. Trends in incidence and mortality in rheumatoid arthritis in Rochester, Minnesota, over a forty-year period. Arthritis Rrheum. 2002;46(3):625-631.

5. Gabriel SE, Michaud K. Epidemiological studies in incidence, prevalence, mortality, and comorbidity of the rheumatic diseases. Arthritis Res Ther. 2009;11(3):229.

6. Symmons D, Turner G, Webb R, et al. The prevalence of rheumatoid arthritis in the United Kingdom: new estimates for a new century. Rheumatol. 2002;41(7):793-800.

7. Haroon N, Aggarwal A, Lawrence A, Agarwal V, Misra R. Impact of rheumatoid arthritis on quality of life. Mod Rheumatol. 2007;17(4): 290-295.

8. Strand V, Singh JA. Newer biological agents in rheumatoid arthritis: impact on health-related quality of life and productivity. Drugs. 2010;70(2):121-145.

9. Taylor P, Manger B, Alvaro-Gracia J, et al. Patient perceptions concerning pain management in the treatment of rheumatoid arthritis. J Int Med Res. 2010;38(4):1213-1224.

10. Graninger W, Gross WL, Raspe H. Quality of life in rheumatic diseases. [Lebensqualität bei rheumatischen Erkrankungen]. Zeitschrift fur Rheumatologie. 2010;69(3):197. German.

11. Her M, Kavanaugh A. Patient-reported outcomes in rheumatoid arthritis. Curr Opin Rheumatol. 2012;24(3):327-334.

12. Khanna D, Tsevat J. Health-related quality of life - an introduction. Am J Manag Care. 2007;13(9):S218-S223.

13. Tugwell P, Idzerda L, Wells GA. Generic quality-of-life assessment in rheumatoid arthritis. Am J Manag Care. 2007;13(9):S224-S236.

14. Bartlett SJ, Hewlett S, Bingham CO 3rd, et al. Identifying core domains to assess flare in rheumatoid arthritis: an OMERACT international patient and provider combined Delphi consensus. Ann Rheum Dis. 2012;71(11):1855-1860.

15. Sanderson T, Hewlett S, Richards P, Morris M, Calnan M. Utilizing qualitative data from nominal groups: exploring the influences on treatment outcome prioritization with rheumatoid arthritis patients. $J$ Health Pshychol. 2012;17(1):132-142.
16. Felson DT, Smolen JS, Wells G, et al. American College of Rheumatology/European League Against Rheumatism provisional definition of remission in rheumatoid arthritis for clinical trials. Arthritis Rheum. 2011;63(3):573-586.

17. Smolen JS, Landewe R, Breedveld FC, et al. EULAR recommendations for the management of rheumatoid arthritis with synthetic and biological disease-modifying antirheumatic drugs. Ann Rheum Dis. 2010;69(6): 964-975.

18. Kievit W, Fransen J, Oerlemans AJ, et al. The efficacy of anti-TNF in rheumatoid arthritis, a comparison between randomised controlled trials and clinical practice. Ann Rheum Dis. 2007;66(11):1473-1478.

19. Sokka T, Pincus T. Eligibility of patients in routine care for major clinical trials of anti-tumor necrosis factor alpha agents in rheumatoid arthritis. Arthritis Rheum. 2003;48(2):313-318.

20. Wolfe F, Michaud K, Dewitt EM. Why results of clinical trials and observational studies of antitumour necrosis factor (anti-TNF) therapy differ: methodological and interpretive issues. Ann Rheum Dis. 2004; 63 Suppl 2:ii13-ii17.

21. Zink A, Strangfeld A, Schneider M, et al. Effectiveness of tumor necrosis factor inhibitors in rheumatoid arthritis in an observational cohort study: comparison of patients according to their eligibility for major randomized clinical trials. Arthritis Rheum. 2006;54(11):3399-3407.

22. Hunt SM, McEwan T.The development of a subjective health indicator. Soc of Health and Illness. 1980;2:231-246.

23. Ware JE, Sherbourne CD. The MOS 36-Item Short-Form Health Survey (SF-36). I. Conceptual framework and item selection. Med Care. 1992;30:473-483.

24. Zink A, Listing J, Klindworth C, Zeidler H, German Collaboratrive Arthritis C. The national database of the German Collaborative Arthritis Centres: I. Structure, aims, and patients. Ann Rheum Dis. 2001;60(3): 199-206.

25. Groessl EJ, Ganiats TG, Sarkin AJ. Sociodemographic differences in quality of life in rheumatoid arthritis. Pharmaco Economics. 2006;24(2):109-121.

26. Mili F, Helmick CG, Moriarty DG. Health related quality of life among adults reporting arthritis: analysis of data from the Behavioral Risk Factor Surveillance System, US, 1996-1999. J Rheumatol. 2003;30(1):160-166.

27. Barton JL. Patient preferences and satisfaction in the treatment of rheumatoid arthritis with biologic therapy. Patient Prefer Adherence. 2009;3:335-344.

28. Ortendahl M. Shared decision-making based on different features of risk in the context of diabetes mellitus and rheumatoid arthritis. Ther Clin Risk Manag. 2007;3(6):1175-1180.

29. Barton JL, Imboden J, Graf J, Glidden D, Yelin EH, Schillinger D. Patient-physician discordance in assessments of global disease severity in rheumatoid arthritis. Arthritis Care Res. 2010;62(6):857-864.

30. Kruger K, Karberg K. Treat-to-target from the perspective of officebased rheumatology. [Treat-To-Target aus der Sicht der niedergelassenen Rheumatologie] Zeitschrift fur Rheumatologie. Oct 2011; 70(8):664-669. German.

31. Griffith J, Carr A. What is the impact of early rheumatoid arthritis on the individual? Best practice and research. Clinical rheumatology. Mar 2001;15(1):77-90.

32. Harter M, Muller H, Dirmaier J, Donner-Banzhoff N, Bieber C, Eich W. Patient participation and shared decision making in Germany history, agents and current transfer to practice. Z Evld Fortbild Qual Gesundhwes. 2011;105(4):263-270. 


\section{Appendix I}

\section{The Rheuma-Liga patient questionnaire}

This questionnaire should help us to learn more about and understand better the experiences and attitudes of persons with rheumatic diseases.

Please check the applicable box or boxes. Please mark only one box per question unless stated otherwise.

\begin{tabular}{|c|c|}
\hline \multirow[t]{3}{*}{ QI. You are... } & A patient with rheumatic disease \\
\hline & A health care professional - go to end of questionnaire \\
\hline & Other - go to end of questionnaire \\
\hline \multirow[t]{2}{*}{ Q2. You are... } & A man \\
\hline & A woman \\
\hline \multirow[t]{6}{*}{ Q3. Your age... } & Below 20 \\
\hline & $20-29$ \\
\hline & $30-39$ \\
\hline & $40-49$ \\
\hline & $50-59$ \\
\hline & 60 or older \\
\hline \multirow[t]{7}{*}{ Q4. Your employment status... } & Employed (full time or part time) \\
\hline & Self-employed \\
\hline & Retired \\
\hline & Student \\
\hline & Unemployed (otherwise) \\
\hline & Disabled \\
\hline & Other \\
\hline \multirow[t]{7}{*}{ Q5. Which kind of rheumatic disease are you suffering from? } & Rheumatoid arthritis \\
\hline & Arthrosis \\
\hline & Ankylosing spondylitis \\
\hline & Juvenile arthritis \\
\hline & Fibromyalgia \\
\hline & Psoriasis arthritis \\
\hline & Another type of rheumatic disease. Please specify: \\
\hline \multirow[t]{5}{*}{ Q6. How would you rate the degree of severity of your rheumatic disease? } & Very low \\
\hline & Low \\
\hline & Moderate \\
\hline & Severe \\
\hline & Very severe \\
\hline \multirow[t]{5}{*}{ Q7. How long have you been suffering from your rheumatic disease? } & Less than one year \\
\hline & $\mathrm{I}-3$ years \\
\hline & $3-5$ years \\
\hline & $5-10$ years \\
\hline & More than 10 years \\
\hline \multirow[t]{6}{*}{ Q8. What was your age at onset of the rheumatic disease? } & 19 or younger \\
\hline & $20-29$ \\
\hline & $30-39$ \\
\hline & $40-49$ \\
\hline & $50-59$ \\
\hline & 60 or older \\
\hline \multirow[t]{5}{*}{ Q9. How would you describe your general health status? } & Excellent \\
\hline & Very good \\
\hline & Good \\
\hline & Reasonable \\
\hline & Bad \\
\hline
\end{tabular}


(Continued)

QI0. Considering the impact of rheumatic disease on your life, how are you doing?

Very good

Rather good

Rather bad

Very bad

QII. How would you rate your quality of life today?

\section{Excellent}

Very good

Good

Reasonable

$\mathrm{Bad}$

QI2. How would you rate the level of pain in the last month due to your rheumatic disease?

No pain

Very low

Low

Moderate

Severe

Very severe

QI3. In the last month, how strongly was your normal work (in- and outside the home) affected by your physical health?
Not at all

Somewhat

Moderately

Rather strongly

Very strongly

Q14. In the last month, how often did you suffer from emotional problems (eg, depressive or anxious moods) as a consequence of your rheumatic disease?

All the time

Most of the time

Sometimes

Seldom

Not at all

Not at all

Somewhat

Moderately

Rather strongly

Very strongly

QI6. Would you tell us how much you were affected by your rheumatic disease during your normal daily activities? Are you able to...

Go to bed and get up independently

Dress yourself, including tie shoes and button a shirt

Walk outside (on level ground)

Run errands/go shopping

Get in and out of a car

Drive a car
Without any effort With some effort With a lot of effort Unable

Without any effort With some effort With a lot of effort Unable

Without any effort With some effort With a lot of effort Unable

Without any effort With some effort With a lot of effort Unable

Without any effort With some effort With a lot of effort Unable

Without any effort With some effort With a lot of effort Unable 
(Continued)

Do housework, such as vacuum cleaning or sweeping

Without any effort

With some effort

With a lot of effort

Unable

Q17. To what extent do you depend on...

Your partner

Very much

More or less

Not at all

Not applicable

Family, friends, etc

Very much

More or less

Not at all

Not applicable

Nurse/caregiver

Very much

More or less

Not at all

Not applicable

Other medical specialist staff

Very much

More or less

Not at all

Not applicable

Q18. The following questions are referring to your activities during a typical day. Is your health status limiting you in any way, and if yes, to what extent?

Exhausting activities, such as running, heavy lifting

Moderately exhausting activities, such as vacuum cleaning

Lifting or carrying shopping bags

Going up some stairs

Walking a few hundred meters

Taking a bath by yourself

Using hands/fingers (for writing, tying shoes)
Strongly restricted

Somewhat restricted

Not restricted at all

Strongly restricted

Somewhat restricted

Not restricted at all

Strongly restricted

Somewhat restricted

Not restricted at all

Strongly restricted

Somewhat restricted

Not restricted at all

Strongly restricted

Somewhat restricted

Not restricted at all

Strongly restricted

Somewhat restricted

Not restricted at all

Strongly restricted

Somewhat restricted

Not restricted at all

\section{Q19. For me it is important...}

To be independent from other people

To go to work or restart working as soon as possible
Very important

More or less important

Not that important

Not important at all

Not applicable

Very important

More or less important

Not that important

Not important at all

Not applicable 


\section{(Continued)}

To participate in normal social activities with family members and friends

To manage household activities

To drive a car by myself

To run errands

To do exercise (sports), to be active

To be mobile inside and outside home

To do recreational activities with my children

Q20. Which medicine are you using to control your disease?
Very important

More or less important

Not that important

Not important at all

Not applicable

Very important

More or less important

Not that important

Not important at all

Not applicable

Very important

More or less important

Not that important

Not important at all

Not applicable

Very important

More or less important

Not that important

Not important at all

Not applicable

Very important

More or less important

Not that important

Not important at all

Not applicable

Very important

More or less important

Not that important

Not important at all

Not applicable

Very important

More or less important

Not that important

Not important at all

Not applicable

Analgesics (painkillers)

Non-steroidal anti-rheumatics (NSARs)

Synthetic disease-modifying anti-rheumatic drugs (DMARDs)

(eg, methotrexate)

Corticosteroids

Biologic therapies (like anti-TNF)

Other

Very satisfied

Satisfied

Neither satisfied nor dissatisfied

Dissatisfied

Not satisfied at all

Q22. To what extent were you involved in the choice of your therapy/drug? Not at all

Just a little

Somewhat

Very much

Q23. The goal of the therapy is to help you maintain your lifestyle, to reduce pain in the joints, to slow down the joint damage and to avoid disability. Considering these aspects, how would you rate the efficacy of your current therapy?

Improved my condition dramatically Improved my condition remarkably

Has improved it somewhat

Did not make any difference 
Deteriorated it a little bit

Deteriorated my condition remarkably

Deteriorated my condition dramatically

Q24. How would you describe the side effects of your current medication?

There are none

There are some side effects which do not really bother me

There are some side effects which occasionally interfere with

my daily activities

Many side effects which frequently interfere with my daily

activities

The side effects are difficult to bear

The side effects are intolerable

Q25. Imagine what the ideal treatment would look like for you. Then check how you would rate the following aspects using a scale from "very important" to "unimportant".

Fast relief of symptoms $(<I$ week)

Sustained positive results ( $>$ I year)

Easy handling of therapy (eg, comfort, patient friendly packaging, etc)

Fast signs of improvement ( $<2$ days)

Absence of side effects (maybe: as little as possible or no side effects)

Low dose of the drug

No loss of efficacy over time

No skin reaction at the injection site

Type of administration (path of application)
Very important

More or less important

Neither important nor unimportant (indifferent)

More or less unimportant

Totally unimportant

Very important

More or less important

Neither important nor unimportant (indifferent)

More or less unimportant

Totally unimportant

Very important

More or less important

Neither important nor unimportant (indifferent)

More or less unimportant

Totally unimportant

Very important

More or less important

Neither important nor unimportant (indifferent)

More or less unimportant

Totally unimportant

Very important

More or less important

Neither important nor unimportant (indifferent)

More or less unimportant

Totally unimportant

Very important

More or less important

Neither important nor unimportant (indifferent)

More or less unimportant

Totally unimportant

Very important

More or less important

Neither important nor unimportant (indifferent)

More or less unimportant

Totally unimportant

Very important

More or less important

Neither important nor unimportant (indifferent)

More or less unimportant

Totally unimportant

Very important

More or less important 


\section{Treatment costs}

No need to increase the dose in the future

Easy self-administration

No need to go to hospital

Needs to be taken or used rarely (eg, fewer injections required)
Neither important nor unimportant (indifferent)

More or less unimportant

Totally unimportant

Very important

More or less important

Neither important nor unimportant (indifferent)

More or less unimportant

Totally unimportant

Very important

More or less important

Neither important nor unimportant (indifferent)

More or less unimportant

Totally unimportant

Very important

More or less important

Neither important nor unimportant (indifferent)

More or less unimportant

Totally unimportant

Very important

More or less important

Neither important nor unimportant (indifferent)

More or less unimportant

Totally unimportant

Very important

More or less important

Neither important nor unimportant (indifferent)

More or less unimportant

Totally unimportant

Q26. What type of treatment would you prefer?

One tablet once a day

Subcutaneous injection, ie, administered below the skin, possibly to self-administer or by someone else at home or in a hospital

Intravenous medication, given by a physician or in a

hospital

Q27. How important is self-administration, without help of someone else?

Very important

More or less important

Neither important nor unimportant (indifferent)

More or less unimportant

Totally unimportant

Q28. For what reason would you recommend the Lower-Saxony Rheuma-Liga?

(Please check all answers that apply)

To participate in the physical training offered by the

Rheuma-Liga

To participate in other offerings of the Rheuma-Liga

To receive information about dealing with the disease

To talk to and communicate with persons who are affected by

the same disease

To meet new people

Other reason such as:

Q28b. If you have specified more than one reason, which of them was the single most important for you?
To participate in the physical training offered the Rheuma-Liga

To participate in other offerings of the Rheuma-Liga

To receive information about dealing with diseases To talk to and communicate with persons who are affected by the same disease

To meet new people

Other reason such as: 
Q29. Do you know anything else offered by the Rheuma-Liga beside the physical training? (Please check all answers that apply)
No

Yes, information events

Written information material

Seminars on various topics

Discussion groups

Dance groups

Occupational therapy groups

Strength training

Pain management courses

Patient education

Special insurance rates

Special travel rates

Counseling in social law

"Mobil" member magazine

Other such as:

\section{General practitioner}

Rheumatologist

Other specialist

Media outlets

Internet

Other patients/affected persons
Q31. How did you find out what the Rheuma-Liga has to offer? (Please check all answers that apply)

General practitioner

Rheumatologist

Other specialist

Media outlets

Internet

Other patients/affected persons

\section{No}

Q32. Have you taken advantage of what the Rheuma-Liga has to offer? (Please check all answers that apply)
Yes, information events

Written information material

Seminars on various topics

Discussion groups

Dance groups

Occupational therapy groups

Strength training

Pain management courses

Patient education

Special insurance rates

Special travel rates

Counseling in social law

"Mobil" member magazine

Other

Q33. Could you imagine yourself using one or more of the following items the Rheuma-Liga has to offer in the future?

Nursing care

Household help organization

Rehabilitation offer (eg, in a rehabilitation center)
Definitely, yes

Rather, yes

Rather, no

Definitely, no

Definitely, yes

Rather, yes

Rather, no

Definitely, no

Definitely, yes

Rather, yes

Rather, no

Definitely, no 


\section{(Continued)}

Physician and medical care (eg, physical therapy, physiotherapy)

Support in getting a second opinion from a physician in a medical question

Support in dealing with social services offices and administrations

Support in dealing with the health insurance company or pension insurance
Definitely, yes

Rather, yes

Rather, no

Definitely, no

Definitely, yes

Rather, yes

Rather, no

Definitely, no

Definitely, yes

Rather, yes

Rather, no

Definitely, no

Definitely, yes

Rather, yes

Rather, no

Definitely, no

Very satisfied

Rather satisfied

Rather dissatisfied

Very dissatisfied

Q35. Could you imagine yourself taking advantage of one or several of the following possible courses offered by the Rheuma-Liga?

Therapeutic back training

Endurance training (eg, walking)

Relaxation techniques/dealing with stress

Nutrition and overweight

Nutrition and osteoporosis

Nutrition and rheumatic disease

Q36. Do you participate in the functional training offered by the Rheuma-Liga?

Q37. How did you find out about the functional training courses offered by the Rheuma-Liga?
Definitely, yes

Rather, yes

Rather, no

Definitely, no

Definitely, yes

Rather, yes

Rather, no

Definitely, no

Definitely, yes

Rather, yes

Rather, no

Definitely, no

Definitely, yes

Rather, yes

Rather, no

Definitely, no

Definitely, yes

Rather, yes

Rather, no

Definitely, no

Definitely, yes

Rather, yes

Rather, no

Definitely, no

Yes

No

Friends/relatives/neighbors

Other members of the Rheuma-Liga

Physiotherapist

Physician

Health insurer

Pension insurance

Rehabilitation center

Others such as: 
Q38. In addition to the functional training, did your physician prescribe you any individual physiotherapy within the past 3 months?
Yes, more than 10 sessions

Yes, 6 to 10 sessions

Yes, 3 to 5 sessions

Yes, I to 2 sessions

No
Q39. How satisfied are you with the following aspects of the functional training?

Course instructor

Group size

Rooms

Hours during which the course takes place

Frequency of the training

Degree of difficulty of the training

The amount to pay for participating in the physical training
Very satisfied
Rather satisfied
Rather dissatisfied
Very dissatisfied
Very satisfied
Rather satisfied
Rather dissatisfied
Very dissatisfied
Very satisfied
Rather satisfied
Rather dissatisfied
Very dissatisfied
Very satisfied
Rather satisfied
Rather dissatisfied
Very dissatisfied
Very satisfied
Rather satisfied
Rather dissatisfied
Very dissatisfied
Very satisfied
Rather satisfied
Rather dissatisfied
Very dissatisfied
Very satisfied
Rather satisfied
Rather dissatisfied
Very dissatisfied

Q40. According to your opinion, what is the effect of the functional training on the following aspects of your condition?

Physical fitness

Physical discomfort

Mood

\author{
Very favorable \\ Somewhat favorable \\ Barely favorable \\ Not favorable \\ Very favorable \\ Somewhat favorable \\ Barely favorable \\ Not favorable \\ Very favorable \\ Somewhat favorable \\ Barely favorable \\ Not favorable
}

Open Access Rheumatology Research and Reviews

\section{Publish your work in this journal}

Open Access Rheumatology Research and Reviews is an international, peer-reviewed, open access journal, publishing all aspects of clinical and experimental rheumatology in the clinic and laboratory including the following topics: Pathology, pathophysiology of rheumatologica diseases; Investigation, treatment and management of rheumatological

\section{Dovepress}

Submit your manuscript here: http://www.dovepress.com/open-access-rheumatology-research-and-reviews-journal

diseases; Clinical trials and novel pharmacological approaches for the treatment of rheumatological disorders. The manuscript management system is completely online and includes a very quick and fair peerreview system, which is all easy to use. Visit http://www.dovepress.com/ testimonials.php to read real quotes from published authors. 